

http://www.diva-portal.org

This is the published version of a paper published in Vård $i$ Norden.

Citation for the original published paper (version of record):

Lundén, K., Baigi, A., Lidell, E., Hildingh, C., Fridlund, B. (2007)

Coronary care unit nurses' outlook on death - their own thoughts as well as those of their patients: a pilot study.

Vård i Norden, 27(3): 9-12

Access to the published version may require subscription.

N.B. When citing this work, cite the original published paper.

Permanent link to this version:

http://urn.kb.se/resolve?urn=urn:nbn:se:hh:diva- 1492 


\section{Coronary care unit nurses' out- look on death - their own thoughts as well as those of their patients: A pilot study}

Karin Lundén, RN MNSc Amir Baigi, MSc (stat) PhD Evy Lidell, RNT PhD Ass Prof Cathrine Hildingh, RNT PhD Assoc Prof Bengt Fridlund, RNT PhD Prof

ABSTRACT

No studies have examined the level of preparedness of $\mathrm{CCU}$ nurses to deal with cardiac patients' death issues. Accordingly, the aim of this pilot study was to explore and describe CCU nurses'outlook on their own as well as their patients' thoughts about death. A pilot study was conducted in 2005 at a University Hospital in southern Sweden. The 63 (93\%) nurses answered a newly established 18-item questionnaire

regarding their own and their patients' thoughts about death.

Descriptive statistics revealed that $90 \%$ of nurses believed that

patients often thought about death. Regarding their outlook on death issues, $41 \%$ were aware of their personal standpoint, 63\% were clear about their plan of action, 34\% showed openness towards their patients and $26 \%$ expressed educational adequacy. These low figures pertaining to both personal and professional

awareness indicate a lack of knowledge and competence. Clinical implications are the provision of various forums at CCUs on this subject and the creation of awareness at all levels of nursing education. Research implications are to further develop the instrument and implement an intervention at the CCU of how to care for dying cardiac patients in a professional manner.

KEYWORDS: cardiac care, death, education, nursing, out-

look

\section{Introduction}

The primary task of nurses wor-

king in a coronary care unit

(CCU) is to monitor and treat

life-threatening conditions (1).

Another task, and one that is just as important, is to care for and understand the cardiac patient's mental condition following an acute cardiac event $(1,2)$. Admission to a CCU involves not only chest pain but also an existential crisis $(1,3,4)$. Recovery can be facilitated by good nursing care $(1,5)$, which requires knowledge and experience of reflecting, not only on cardiology but also on cardiovascular nursing (6). CCU nurses are confronted on a daily basis by cardiac patients who have thoughts about as well as fear of death. A review of the appropriate literature revealed no studies that examined the level of preparedness of CCU nurses for answering questions about death or whether they had reflected on these issues, which are of major importance in order to understand a seriously ill or dying patient in his/her existential crisis. However, there is a need for CCU nurses to study and learn more about the death process in order to understand a dying patient, as inability to do so may lead to anguish, guilt and agony for the latter (7). A cardiac event threatens the foundations of life; selfimage, life itself and everything that is considered important (1). Patients in the final stage of heart failure think about death mainly in connection with complications in their condition (8). Although some are in favour of euthanasia or suicide, all patients nevertheless want life-prolonging treatment. There are different opinions about when to initiate a conversation about death (9). Physicians' and nurses' attitudes affect patients and their families. The physician is responsible for informing about the patient's condition, but the nurse has a closer relationship with the patient, which makes it easier for the latter to confide his/her innermost thoughts in the nurse $(9,10)$. This close relationship may imply that the nurse is the most appropriate person with whom to discuss questions and thoughts about death (10). CCU nurses consider communication with dying patients to be an effective therapeutic resource (11), but they have difficulties dealing with their own feelings, leading to dissociation in the dialogue about death $(11,12)$. Very few physicians talk to their patients about the latter's end-of-life wishes (13). Nor is it a matter of course for seriously ill patients to discuss their wishes with relatives. It is therefore important that the members of the seriously ill patient's social network are sensitive to whether he/she wants to talk about death. It is important to identify not only the patients' perception of good and bad death but also how these factors contribute to a death that is consistent with the patient's wishes (14). Due to insufficient knowledge of patients' thoughts about death, it is particularly important to ascertain the attitude of CCU nurses towards the need of cardiac patients to discuss thoughts about death. Accordingly, the aim of this pilot study was to explore and describe the outlook of CCU nurses on their own as well as their patients' thoughts about death.

\section{Material and methods}

Design and setting

A pilot study with a descriptive design was employed, which had been approved by the Institutional Review Board of a University Hospital in southern Sweden. The fact that a pilot study was used was due to methodological limitations, in particular a small sample as well as a lack of data collection instruments. The pilot study was conducted in spring 2005 at a 19-bed CCU and involved registered and assistant nur- ses, all of whom were informed verbally and in writing that participation was voluntary, in line with the Helsinki declaration, and that confidentiality was guaranteed (15).

\section{Participants}

All 68 nurses at the CCU were invited to participate, and 63 (37 registered and 26 assistant nurses) agreed after one reminder. The dropout rate of five $(7 \%)$ was due to lack of time.

\section{Questionnaire}

A questionnaire addressing the outlook of CCU nurses on their own and their patients' thoughts about death was designed specifically for the study by an experienced CCU nurse research team and initially comprised 55 items at ordinal level (from 1=totally agree to $4=$ totally disagree) in the areas of socio-demographics, personal and professional outlook on death. In order to ensure measurability and manageability in clinical practice (i.e. thus avoiding a time-consuming questionnaire), the items were reduced to around 5 per area. One key item: 'I think the patient often entertains thoughts about death' was formulated, in addition to another 12 items, for the purpose of further testing the construct validity (explorative factor analysis) and internal consistency reliability (Cronbach's alpha co-efficient) by means of tests on three experienced CCU colleagues (registered as well as assistant nurses) and negotiated consensus (16) within the CCU research team. The factor analysis revealed four factors with factor loadings $>.4$, labelled to the essence: plan of action, 4 items; personal standpoint, 3 items; openness towards patients, 3 items; and educational adequacy, 2 items, which cumulatively explained $61 \%$ of the total variance and had an overall Cronbach's alpha coefficient of .66 (Table 1). Five further sociodemographic items were inclu- 


\section{Table 1: The development of the coronary care unit nurse outlook questionnaire by means of a factor analysis comprising principal component. analysis with varimax rotation (construct validity) and Cronbach's alpha coefficient (internal consistency reliability)}

\section{Outlook/item}

\section{Plan of action}

I have a clear viewpoint concerning my thoughts about my own death

I feel comfortable talking about death

I think there are good opportunities for dealing with ones feelings after a case of death during work

I know where to turn to talk to somebody when I am having a difficult time after a case of death during work

Personal standpoint

I usually talk about death in private life

It is important for me to say goodbye to deceased patients that I have cared for

I willingly talk to dying patients since I find it interesting to hear their view concerning death

Openness towards patients

I often start a conversation that shows the patient that I am willing to talk about death

I often consider what has been good or bad about the care after a case of death

I find that patients often want to talk about death

Educational adequacy

I do not think there is a need for education/therapy groups at work in the form of «conversations about death»

I think that I have gotten enough knowledge from school education to know how to deal with dying patients

Total (all items)

Communalities Factor loading Per cent explained Cronbach's alpha variance per area

0,540

0,790

0,683

0,661

0,703

0,687

0,601

0,754

0,335

0,335

0,466

0,637

0,785

0,649

0,711

0,602

0,775

0,637

0,463

0,715

0,568

0,588

0,738

0,522

0,850

60,7
0,54

\section{0,55}

0,37

\section{ha}




\begin{tabular}{|c|c|c|}
\hline Variable & Number & $\%$ \\
\hline \multicolumn{3}{|l|}{ Age } \\
\hline$<40$ yrs & 35 & 56 \\
\hline$>40 \mathrm{yrs}$ & 28 & 44 \\
\hline \multicolumn{3}{|l|}{ Profession } \\
\hline registered nurse & 37 & 59 \\
\hline assistant nurse & 26 & 41 \\
\hline \multicolumn{3}{|l|}{$\operatorname{Sex}$} \\
\hline $\operatorname{man}$ & 11 & 17 \\
\hline woman & 52 & 83 \\
\hline \multicolumn{3}{|c|}{ Work experience at $C C U$} \\
\hline$<10$ yrs & 32 & 51 \\
\hline$>10 \mathrm{yrs}$ & 31 & 49 \\
\hline \multicolumn{3}{|l|}{ Civil status } \\
\hline cohabiting & 47 & 75 \\
\hline living alone & 16 & 25 \\
\hline
\end{tabular}

death in their private life. A similar number $(n=34 ; 55 \%)$ considered it important to say goodbye to a deceased patient they had cared for, while around one in five $(n=14 ; 22 \%)$ welcomed the opportunity to talk to dying patients since they found it important to hear the latter's views concerning death.

Openness towards patients In total, 21 (34\%) of the CCU nurses exhibited openness towards their patients regarding death issues. After a death, around three in four $(\mathrm{n}=48 ; 77 \%)$ reflected on what had been good or bad about the care, while slightly more than one in ten $(\mathrm{n}=8 ; 13 \%)$ often initiated a conversation showing the patient that he/she was willing to talk about death. The same number $(\mathrm{n}=8 ; 13 \%)$ considered that patients often wanted to talk about death.

\section{Educational adequacy}

A total of 16 (26\%) CCU nurses stated that they had had an adequate training regarding death issues. Approximately one in three $(n=23 ; 37 \%)$ considered that ther scrutinised by means of validity and reliability tests in order to establish safety. So far, however, the figures are promising, comprising a total variance explaining $>60 \%$, satisfactory factor loadings $>.4$, in addition to a Cronbach's alpha coefficient of just below the recommended .70 (18), in addition to the fact that we also employed a pilot study and reached negotiated consensus (16). The addition of further items, especially in the educational adequacy factor, could possibly increase the internal consistency reliability value by means of a higher Cronbach's alpha coefficient. Furthermore, experienced CCU nurse researchers developed the questionnaire, and the number of items was reduced to facilitate use in clinical practice. Thirdly, proper accuracy in terms of precision and carefulness was achieved as the items were designed to be answered easily and quickly by means of a Likert scale by CCU nurses with vast experience of the subject in question, which also explains the very high response rate of $93 \%$ patients.

\section{Discussion}

\section{Methodological issues}

To our knowledge, this pilot study is the first attempt to study CCU nurses' outlook on thoughts of death, and for this reason the findings must be considered of importance for clinical practice. However, there are several limitations that must be taken into account before any generalisations can be made (17): firstly, applicability in terms of the design and sample can be questioned, due to the fact that this was an explorative and descriptive pilot study with a small and disparate sample comprising both registered and assistant nurses. With a larger sample it would have been possible and also necessary to take care of any influence of socio-economic factors. Secondly, the questionnaire was specially designed for this study and needs to be furhan half reported satisfactory ortunities for dealing with heir feelings at work in ord alleviate anguish, guilt or agony, fact highlighted by Civetta (7) Jonsson and Segesten (20) also discussions are necessary in order consider that conversations and to be able to internalise traumatic experiences. This indicates that the methods for dealing with these issues on the ward are in need of improvement. Only two fifths were aware of their personal standpoint, as indicated by their willingness to talk to dying patients in order to ascertain the latter's viewpoints concerning death Communication would be facilitated if CCU nurses were to adopt such an approach, as dealing with psychological aspects of the disease should be a part of their professional duties $(9,10)$. Crafoord (2) deplores the physician's lack of time and considers that the psychological reactions to death ought to be dealt with in a doctorpatient relationship characterised by a dialogue that continues by means of follow ups. Lack of time is a factor that contributes to the low level of trusting relationships. One in three CCU nurses, a fairly low figure, reported being open towards their patients. This reveals that most nurses neither initiated a conversation showing their willingness to talk about death nor considered that the patients wanted to talk about it. Nevertheless, a cardiac event threatens the foundation of life (1), which is the reason CCU nurses must act more openly in order to provide patients with a better opportunity to discuss their thoughts and thus obtain help to deal with their feelings. It is the CCU nurses' own feelings of fear and insecurity that hinder conversations about death (11). At the same time, it is important to be sensitive to and respect the patient's integrity (13, $21)$. However, psychological discomfort is common after a cardiac event, while stress is a contributing factor in recurrence (22). If CCU nurses were to employ suitable conversational techniques, it could result in less stress and fewer recurrences. With regard to educational adequacy, there is a great need for education in this area, as only one in four of the $\mathrm{CCU}$ nurses were satisfied. This is 
in line with findings in other healthcare areas and indicates that university colleges do not support end-of-life care, which means that this aspect must be taken seriously and receive greater attention (23-25). Students imply that caring for dying patients can only be learned through clinical practice (24), which strengthens this study's finding regarding the need for in-service therapy groups. Education at the workplace by well-trained supervisors and by specialists during nursing studies is probably the best option.

\section{Conclusions and implications}

This pilot study has produced promising figures regarding the questionnaire's validity and reliability. However, further improvement by expanding the questionnaire as well as using larger samples are necessary in order to make any generalisations. Nevertheless, the CCU nurses' outlook $(n=63)$ on their own as well as their patients' thoughts about death showed that nine out of ten considered that the patient often had such thoughts. Furthermore, two out of three had a clear action plan, two out of five were aware of their personal standpoint, one out of three were open towards their patients, while one of four expressed educational adequacy regarding thoughts of death. The low figures pertaining to both personal and professional outlook indicate a lack of knowledge and competence on the part of these highly experienced CCU nurses. The clinical implications are to provide different forums in CCUs in order to address the subject, as well as highlighting the insufficiency in this area at all levels of nursing education. A nursing research implication is to introduce an intervention in a CCU for the implementation of professional factors related to how to care for dying patients or those who have thoughts of death.

\section{Accepted for publication \\ 25.11.2006}

Karin Lundén, RN MNSc $(1,2)$

Amir Baigi, MSc (stat) PhD (3)

Evy Lidell, RNT PhD Ass Prof

$(2,3)$

Cathrine Hildingh, RNT PhD

Assoc Prof (2,3)

Bengt Fridlund, RNT PhD Prof (2-4)

(1) Coronary Care Unit, University Hospital Lund, Lund, Sweden (2) School of Health and Social Sciences, Halmstad University, Halmstad, Sweden

(3) Dept of Primary Health Care, Göteborg University, Göteborg, Sweden

(4) School of Health Sciences and Social Work, Växjö University, Växjö, Sweden

Contact person:

Bengt Fridlund, professor

School of Health Sciences and

Social Work

Växjö University

SE - 35195 Växjö

bengt.fridlund@vxu.se

+46-470-70 83 12;

+46-703-88 8312

\section{References}

1. Hatchett R, Thompson D. Cardiac Nursing. Edinburgh; Churchill Livingstone, 2002.

2. Crafoord C. The Worry of the Heart. Natur och Kultur; Stockholm, 2004. (In Swedish)

3. Clements PT, Stenerson HJ. Surviving sudden loss: when life, death, and technology collide. J Vasc Nurs 2004;22:134-7.

4. Hammond BB. Nursing assessment of blunt cardiac trauma. Nurs Clin North Am 1986;21:677-84.

5. Cowan MJ, Pike KC, Budzynski HK. Psychosocial nursing therapy following sudden cardiac arrest: impact on two-year survival. Nurs Res 2001;50:68-76.

6. Fridlund B, Mårtensson J. Cardiovascular nursing in $\mathrm{RN}$ and higher education in Swedish universities: a national survey. Eur J Cardiovasc Nurs 2004;3:255-9.

7. Civetta JM. Critical palliative care: intensive care redefined. Surg Oncol Clin North Am 2001;10:137-59.

8. Willems DL, Hak A, Visser F, Van der Wal G. Thoughts of patients with advanced heart failure on dying. Palliat Med 2004; 18:564-72.

9. Guirardello Ede B, RomeroGabriel CA, Pereira IC, Miranda AF. The patients' perception during their stay in the intensive care unit. Revista da Escola de Enfermagem da USP. 1999;33:123-9.

10. White G, Su HR. Am I dying nurse? Nurs Prax NZ 2000;15:33-40.

11. Trovo de Araujo MM, Paes da Silva MJ. Communication with dying patients - perception of intensive care unit nurses in Brazil. J Clin Nurs 2004;13:143-9.

\section{Deffner JM, Bell SK. Nurses'} death anxiety, comfort level during communication with patients and families regarding death, and exposure to communication education: a quantitative study. J Nurs Staff Dev 2005;21:19-23.

13. Kahana B, Dan A, Kahana E, Kercher $\mathrm{K}$. The personal and social context of planning for end-of-life care. J Am Geriatr Soc 2004;52:1163-7.

14. Vig EK, Pearlman RA. Good and bad dying from the perspective of terminally ill men. Arch Intern Med 2004;10:977-81.

15. World Medical Association
Declaration of Helsinki. Ethical Principles for Medical Research Involving Human Subjects. Tokyo; World Medical Association, 2004.

16. Göransson A, Dahlgren LO, Lennerstrand $\mathrm{G}$. Changes in conceptions of meaning, effects and treatment of amblyopia. A phenomenographic analysis of interview data from parents of amblyopic children. Patient Educ Couns 1998;34:213-25.

17. Fridlund B, Hildingh C. Qualitative Research Methods in the Service of Health. Lund; Studentlitteratur, 2000, pp 13-25.

18. Burns N, Grove SK. The Practice of Nursing Research: Conduct, Critique and Utilization ( $5^{\text {th }}$ ed.). Philadelphia; Saunders, 2005.

19. van Elderen T, Maes S, Dusseldorp E. Coping with coronary heart disease: a longitudinal study. J Psychosom Res 1999;47:175-83.

20. Jonsson A, Segesten K. Guilt, shame and need for a container: a study of post-traumatic stress among ambulance personnel. Acc Emerg Nurs 2004;12:215-23.

21. Health and Medical Services Act. 1982:763 §2a. Stockholm; Ministry of Health and Social Affairs, 1982. (In Swedish)

22. Clark AM. «It's like an explosion in your life...»: lay perspectives on stress and myocardial infarction. J Clin Nurs 2003;12:544-53.

23. Silveira MJ, DiPiero A, Gerrity MS, Feudtner C. Patients' knowledge of options at the end of life: ignorance in the face of death. JAMA 2000;15:2483-8.

24. Wear D.»Face-to-face with It»: medical students' narratives about their end-of-life education. Acad Med 2002;77:271-7.

25. Sullivan AM, Lakoma MD, Block SD. The status of medical education in end-of-life care: a national report. J Gen Int Med 2003;18:685-95. 